Supplement of

\title{
The strengthening relationship between Eurasian snow cover and December haze days in central North China after the mid-1990s
}

\section{Zhicong Yin and Huijun Wang}

Correspondence to: Zhicong Yin (yinzhc@163.com)

The copyright of individual parts of the supplement might differ from the CC BY 4.0 License. 

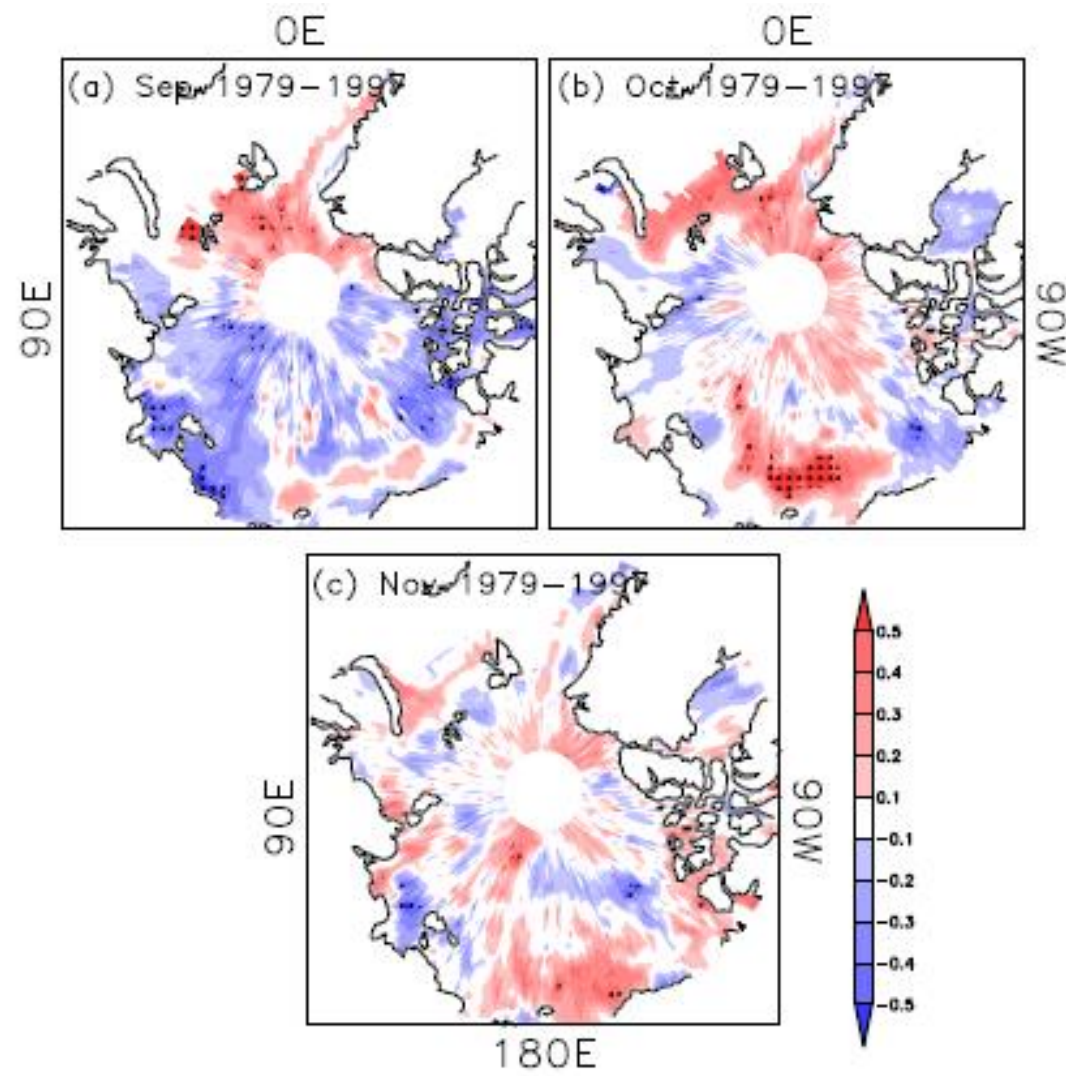

Figure S1. The CC between $\mathrm{SC}_{\mathrm{ES}}$ and September (a), October (b) and November (c) Arctic sea ice from 1979 to 1997 after detrending. The black dots indicate CC exceeding the 95\% confidence level ( $\mathrm{t}$ test). 

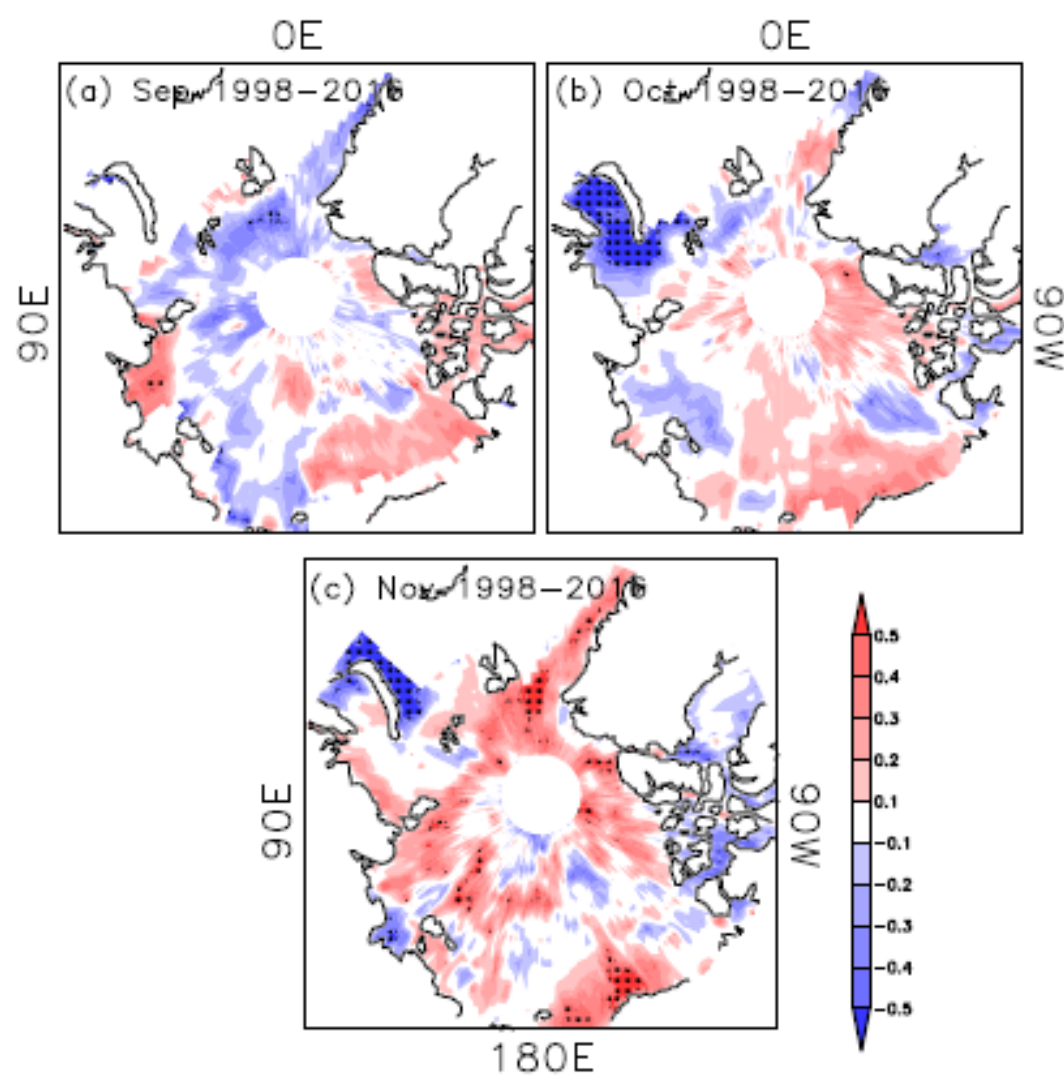

Figure S2. The CC between $\mathrm{SC}_{\mathrm{ES}}$ and September (a), October (b) and November (c) Arctic sea ice from 1998 to 2016 after detrending. The black dots indicate CC exceeding the 95\% confidence level ( $\mathrm{t}$ test). 


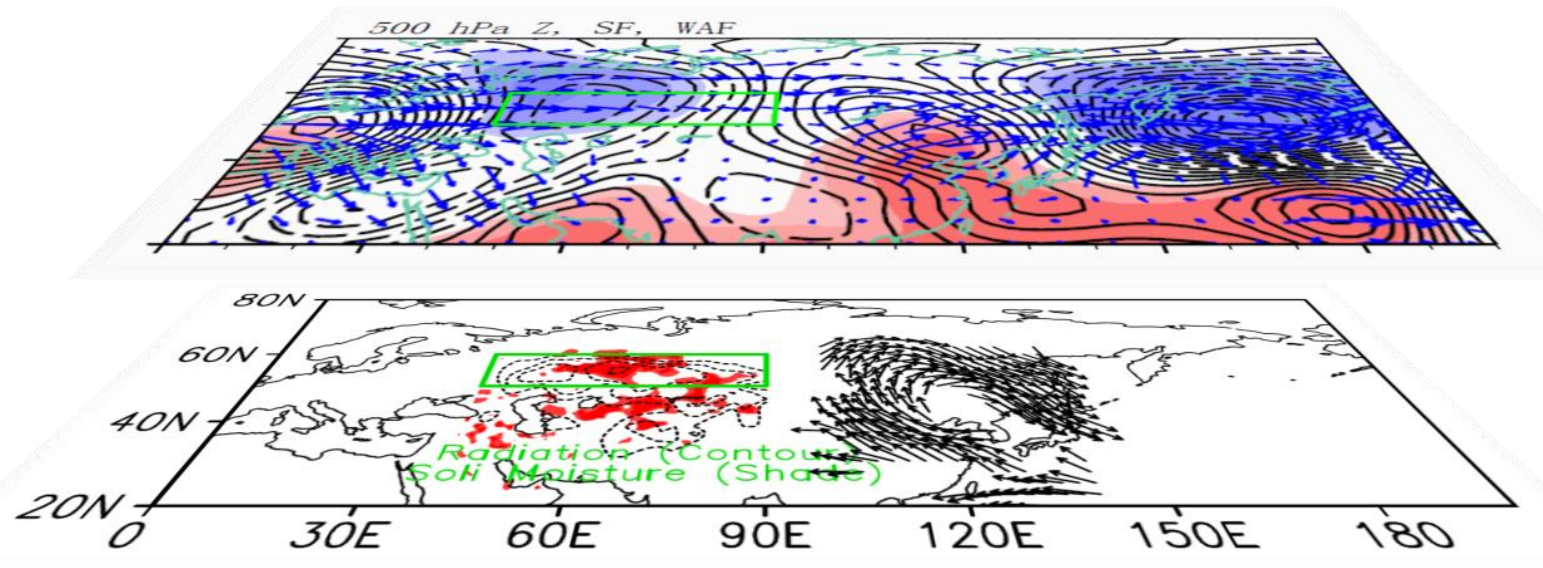

Figure S3. Diagram of the associated physical mechanisms. Near surface, the ON radiation (contour) and soil moisture (shade) were influenced by the $\mathrm{SC}_{\mathrm{ES}}$. On the mid-high level, the teleconnected Rossby wavelike pattern propagated into the Central North China, representing by Z500 (shade), stream function (contour) and wave activity flux (arrow). Finally, the local anti-cyclonic circulation near surface (arrow) led to weak ventilation conditions in December. 